\title{
Impact of Computerized Banking Monitoring Information System onthe Performance of Nigerian Banking Industry. (A Case Study of Zenith Bank Plc.)
}

\author{
1samuel Olumuyiwa Olusanya, Oluremi Adelowo, Babatunde Jelili Sufian \\ National Open University ofNigeria, SchoolOf Art andSocial SciencesEconomics Unit, \\ National Open University Of Nigeria, SchoolOf Management Science Operation Unit \\ Lecturer school Of Management Sciences nationalOpen University ofNigeria, Victoria Island, Lagos.
}

\begin{abstract}
The paper vividly takes a look at the implementation of computerized banking monitoring system in Nigeria banking industry using Zenith bank Nigeria Plc as a case study. Moreover, Computerized banking monitoring information system in Nigerian banking industry is one of the ways the bankers try to reduce fraud and some other irregular activities in transferring cash online. However, the paper makes use of primary data of questionnaires analysis that were distributed to one hundred and fifty (150) staffs of Zenith bank Nigerian Plc. Three hypotheses were tested using spearman's rank correlation coefficient and the result shows thatthe lacks of security on the current automates system has a significant effect on internet banking services and the cost of implementing computerized banking monitoring information system has a significant effect on Zenith bank Performance in Nigeria banking industry. More so, the third results shows that the feasibility in installing computerized monitoring system has a significant effect on banking activities in Zenith bank. Therefore the paper concludes and recommends that when considering using computer monitoring software in the workplace like the banking industry, thorough and extensive research on the technology should be done and the bank should make sure that the monitoring information system in the industry is very efficient and effective in detecting fraud and other irregulaties related to online transaction.
\end{abstract}

Keyword: Computerized banking System, Nigerian banking industry, Spearman's rank correlation coefficient, Zenith bank, online transaction, Computer monitoring software.

\section{Introduction}

The greatest innovation that has taken place in the twenty-first century is in the innovation of information technology. This is currently made possible by the introduction of the digital computers, which has been observed in the field of communication to be increasingly inseparable from communication. This linkages often referred to as amplified by business trends the technology and business, foster growth in network systems that use communication links to connect subsidiary system (nodes) which may sender and receive direct and information to sender and receiver. (Awaju, 2013)

However, according to Hamoli (2013), he assert that talking of the internet a couple of years ago would have sound link a fair table but today the internet is pervasive in almost every field of human endeavor changing the fundamentals of how we conduct the nation as well as international business. Few years of existence, the internet information in Banking has shown that it can sliver the long sought after goal of electronic commerce. It is worth noting that companies in developed countries world-wide have recognized the business potential of the internet and are getting connected to the network and consider it to be relevant to their customers in terms of the services they provide in the twenty first century and in the future most append this services provide by E-commerce in the banking system in order to stay in competition. Now that an on time banking is the one thing bank should get up and invest in internet technology information monitoring system to reap bounteously the benefit accruing from web banking.

Furthermore, the advances in the world of information technology is almost recorded on a daily basic consequently rendering former communication equipment obsolete as people look toward the improved electronics that support E-commerce made possible through the use of the internet in the banking sector.

Although, a significant improvement has been recorded in the use and development of information technology monitor in the banking industry over the last decade. Most banks are still far from implementing technologybased strategies able to see them through competition in banking markets. This may be as a result of lack of awareness, the inability to evaluate the benefit derived from the use of the recent technological development (internet) and capital shortage that may hamper the design and subsequent implementation of the technological tool hence denying customer of this advances services and their flexibility choice and convenience associated with the internet banking. (Sanya, 2014) 
The advantage offered by these services calls for a review of the existing automated system and subsequent design and implementation of computerizes banking monitor system site to improve the existing system.

Finally, the paper will tends to investigate the lacks of the current automates system in terms of modern technology that support internet banking services and suggest ways of updating them and to examine the cost of design and implementation of computerized banking monitoring information on the Zenith bank Performance in Nigeria and to also examine the feasibility in installing computerized monitoring system on banking activities in Zenith bank in Nigeria.

\subsection{Internets As An Information Tool}

\section{Literature Review And Theoretical Framework}

Aganga, (2012),assert that the internet information is a global network of computers. It links independent microcomputers to end computers, Local area network, wide area networks and wide world network together in such a way that they share information hard and software resources. It is in effect a global network of computers. Millions of computers scattered all over the world are presently linked to the internet these computer network communicate with each other in accordance with some internationally accepted and standardized rules or protocols.

It is effect the numerous advantages accruing from the use of this great tool called internet has found its way into the bank hence internet banking system has been of great concern to many individuals and corporate organization and this has dominated most captions in journals, magazines, news, letter published by the media or contributions made by individuals in the form article and seminar and presentation. Adams (1991) in his article stated that as the stethoscope is to the doctor, so is the computer to the banker and that the latest bug in the industry is the installation of the on-line real system which through the cashier, the customer can have on- the-spot balance of second or third day confirmation of the balance is emphases that the use of network system are related to banks with wide branch network and those with large customer based. In line with the above the Zenith Bank Plc monthly business economic report (1991) comments that most bank face a lot of problem when dealing with their customer because they cannot cope with the ever increasing demand imposed on them by customers.

Most of those banks lose their clientele because of lack of structures and the use of obsolete banking techniques in their operations for such bank to compete favorably with others there is the need for them to update on their existing structure to keep afloat in the competitive banking sector. It is at this point that much emphasis is made in the introduction of a computer based information system to improve on the services they render, though the project requires a colossal financial outlay to implement.

Furthermore, talking about the internet in banking operation, Brown (1999) said that the internet in its evolving state is becoming a serious method of business communication and data transfer. As such bank and other financial institution are beginning to use the internet as new vehicles for doing business. The internet allows banks to offer both new services with the convenience of interact from any computer capable of making the appropriate conduction. Again, white paper on the internet by Adelabu (1999) said that the general acceptance of the internet makes it the ideal way for bank to reach a wide retail market without the expense of operating and resources additional branches. In support of the internet banking, find article, coming one of their brief article on-line resource and 724 solution seam to deliver wireless and payment services to regional and community financial, institution said that on-line resources on internet application service, provides to financial institution announced that its 500 financial institution charts could soon be offering their customers secure wireless access to their financial information.

However, Dawson, (2012), said in an agreement with 124 solutions the services will allow financial institution high value customer to securely access online financial services through data assistants through the USA. The alliance with 124 solution continues on-line resource commitment to multiple access devices and offering its clients a solution that provides greater customer access and customization in like manner computer weekly, find entire form contributed that the adoption of internet banking across Europe is set to soar over the next few years with 25 millions user expected by 2005 according to new research.

In its survey and banking technology in Europe 2001 data monitor predated that technology expenditure with in this sector will double between 2000 and 2005, rising from 2.7bn to and 5bn (1.9-3 5bn found). In another issue titled cotillion introduce new version of internet banking system voyager 3.0 report, internet business new (S) 1995-2001 MZ communication Ltd, said that the us-based E-finance system provider cotillion has launched voyager 3.0 the latest version of its internet banking platform.

Voyager 3:0 is a real time system designed to give financial institution a scalable and flexible foundation for the delivery of E-finance services to their customer. Enhancement in this version include multifinancial institution configurations, Multilanguage and currency support an increased authorization and authentication services such as single sign on off host user authentication and user entitlement management internet banking as with traditional banking method security is a primary concern. 
(Brown 1999) internet banking means banking that exist solely on the internet and have no physical presence for consumer to internet with the institution in other works there is no physical customer, and information system are located in the "virtual" world. However, like real banks various banking activities and transaction 90 as usual with necessary safe guard in place, internet banking in the concept of developed continues is not just a shallow blitz of a new market tool but a solid business communication tool with very reasonable security regulatory and customer privacy concern.

In support of the above text the united states of American for example established acts relating to information technology and banking sector which include; the right to finance privacy acts (REPA) passed in 1978, which among others disallows government access to the bank records.

The banking security acts which lay out the type of records that must be maintained by banks as well as provide banking regulations.

Still talking about security, Bill (2001) in his article titled visa pusher E-tailors to prove internet security said that credit and companies are putting pressure on E-tailor to prove that I.T system are secure as part of a drive to raise the public confident in buying over the internet.

This move follows concerns that e-commerce is being held back by the unwillingness of shoppers to give their credit card detail out on the web. More so, Figure from the association of payment Dearing services released that on-line fraud is deterring both retailer and customers from trading on-line. Credit and company visa is pressing commercial web site to comply with its singing security regulations in attempt boost indigence in online trade.

However the initiative is likely to cause controversy particularly among long retailer to prove to visa that their system are secure. In his first stage of the program the United States has the largest E-commence.

Suite in Europe to have independent auditors that meet rigorous on visa security standard.

Although smaller organizations will not be regarded to have audits. They will be expected to bring in security expert from their backs or private security consultancies appareled by visa to help them meet standards.

Williams (2001) president of fraud management at visa said; we are mindful of cardholders concerns rewardingly. Visa wants to create a better and says internet shopping experience in another issue, internet banking personal, privacy security Brown explained thus-due to the perceived problem with the openness of the internet. The issue of share transaction is a primary concern in internet barreling. Internet bank use latest methods in internet banking system security to increase and monitor the integrity of on-line banking applications. Most internet banks evolve a three level security of customer information as it is said from the customer personal computer to the web server. However, the second area concern the severity of the environment in which the internet banking server and customer information data base reside. Finally security measures are in place to prevent unauthorized user from attempting to log into the on-line banking section to the web site.

Data security between the customer browser and the web server is handled through a security protocol called secure socket layer (SSL). SSL provides data encryption server authentication and message integrity for an internet connection.

Furthermore, Kooker (2014) a security analyzer constantly monitors login attempts and recognizes taller that could inculcate a possible unauthorized attempt to log into account. When such trends are observed steps are taken automatically to present that account from being used.

Security concern have been addressed from every angle within the architecture of the internet banking application implementation of the SSL, security browser ensures authenticated data has been received from the customer.

Finally, the security analyzed monitors log on attempts in order to prevent unauthorized logins. It is very interesting to note that internet banking has advances to television (TV) banking. Computer weekly article titled nationwide launches digital TV banking services. Goes on to say that United Kingdom building services nationwide has launched a digital TV banking services to extend its multi-channel banking and the services available through bush internet active set-top boxes, will allow customer to access their account balances and statement and allow them to transfer money between accounts.

\subsection{Theoretical Framework}

\subsubsection{Complexity Theory For Testing Computers.}

Buffalo (2012), in his mathematical approach said complexity theory can be more effective than current methods used by manufacturers of computer hardware and software to test performance claims or benchmarks for their products, according to computer scientists at the University at Buffalo (UB). Using the methodology, they recently randomly generated a test utilizing high-precision division arithmetic that pinpointed the flaw in the Pentium computer chip.

Cai (2011), associate professor of computer science at UB, said that prototype benchmarks using complexity theory developed by him and his colleagues and students have the potential to test computer 
hardware for a range of variables, including processor speed and memory capacity, as well as specific software packages. The purpose of a benchmark is to verify a manufacturer's performance claims about the speed and accuracy of a specific product, Cai explained. Problems may get past design teams, he noted, because current benchmarks are not rigorous or objective enough. By subjecting products to a problem with a specified complexity, Cai said, manufacturers could prevent or correct design flaws before they hit the market.

Most benchmarks require that the hardware or software being tested be able to run specific sets of data in a specific amount of time, he said. But because the benchmarks are known to all manufacturers in advance, the test results are not always trustworthy. What is missing from the current generation of benchmarks, Cai believes, is an objective criteria and a certain amount of randomness in generating the actual test that will provide a realistic assessment of how a product will perform under the most demanding and unpredictable computational conditions.

Cai and Lipton (2012), computer science professor at Princeton University and co-investigator on a National Science Foundation grant, argue that a benchmark based in computational complexity would be more accurate because it would safeguard against "loopholes" in current benchmarks that allow some errors to go undetected.

Computational complexity tries to classify computational problems according to their complexity mathematically, said Cai. Physical laws place limits on you, he said for example, they tell you have to spend a certain amount of energy to accomplish certain tasks. Computational complexity places similar limits on computational processes. There are things you cannot do in a certain amount of time and space, according to computational complexity theory. According to Cai, this characteristic can enhance computer security. If the computational complexity of deciphering a secret message from scratch is extremely hard mathematically, you can be assured that your 'enemy' cannot do it without what's known as a 'trapdoor,' whereas your 'friend,' who has the 'trapdoor' can recover it easily," he said.

However, finally, Young (2010) assert that the complexity theory also makes use of monitoring system in the banking transaction to view different activities that go on the bank's web. However, the system can view various account transactions from one branch of the bank to the other. However, any movement of cash electronically, the monitoring information system will alert and detect any false transaction from any branch or from any other bank transfer. These technology was developed to safeguard the customer's transaction and cash movement from one bank to the other and also help the bank to know the exert area where there is false cash movement. So majority of the banks now embraces the use and implementation of computerize monitoring system on bank performance.

\section{Methodology}

The data used in this research study was basically primary data of questionnaire analysis, that will be distributed to the Staff of Zenith bank Nigeria Plc, head office. However, the study population comprises 120 Staff of Zenith bank Nigeria Plc and it is made up of only the male and female. More so, the population also has different material status from single to married. However, spearman's rank correlation coefficient is adopted as the estimation techniques and the formula is specified as follows:

$$
\mathrm{R}^{2}=1-\frac{6 \sum \mathrm{d}^{2}}{\mathrm{n}\left(\mathrm{n}^{2}-1\right)}
$$

where : $d=$ the different between the ranks of each pair $\mathrm{n}=$ number of paired observations

\section{Analysis Of Questionnaire}

Q1: Computerized banking Monitor information is good in the banking industry.

The result reveals that 148 out of 150 respondents strongly agree that Computerized banking monitor information is good in the banking industry and this represents $98.67 \%$ of the total respondents while 2 out of 150 respondents agreed with the motion and this gives $1.33 \%$ of the whole respondents. We can then conclude that Computerized banking Monitor information is good in the banking industry.

Q2: Your bank (Zenith bank) uses computerized monitoring technology.

The result shows that 135 and 15 respondents strongly agreed that Zenith bank uses computerized monitoring technology and this represent $94.67 \%$ of the total respondents while only 8 respondents agreed with the motion and this gives $5.33 \%$ of the whole respondents. Therefore we can then conclude that leadership and motivation affect productivity level

Q3: The computerized monitoring system has help your bank (Zenith bank) to detect dubious transactions made by some customers.

The table above results that 144 respondents strongly agree and this gives $96 \%$ of the while respondents while 6 respondents agree on the notion and this gives $4 \%$ of the whole respondents. Therefore we can then conclude 
that the computerized monitoring system has helped their bank (Zenith bank) to detect dubious transaction made by some customers.

Q4: The management of Zenith bank gives priority to computerized system technology to meet the goal and aspiration of the customers.

The table above shows that 122 out of 150 respondents strongly agree with the question and this gives $81.34 \%$ of the total respondents while 29 out of 150 respondents agree with the motion and this $13.33 \%$ of the total respondents 8 respondents strongly disagree with the motion and this constitutes $5.33 \%$ of the total respondents. Therefore, we can then conclude that the management of Zenith bank gives priority to computerized system technology to meet the goal and aspiration of the customers.

Q5: Poor Leadership Performance has negatives on employee's performance even though there is good computerized networking.

142 respondents strongly agree with the question and this gives $94.67 \%$ of the wholes respondents, 8 respondents agree with the question and this represent $5.33 \%$ of the total respondents. Therefore, we can then conclude that Poor Leadership Performance has negatives on employee's performance even though there is good computerized networking.

Q6: The implementation of computerized banking monitor information system has helped your bank (Zenith bank) to detect fraud among the staffs.

144 respondents strongly agree with the question and this constitutes $967 \%$ of the total respondents, 6 out of 150 respondents agree with the question and this gives $4 \%$ of the total respondents. Therefore, we can then conclude that bad welfares is an obstacles for employees performance and poor productivity in an organizationand that implementation of computerized banking monitor information system has helped their bank (Zenith bank) to detect fraud among the staffs.

Q7: Fraud can liquidate a bank if is not properly managed with good monitoring information.

The result shows that 105 out of 150 respondents strongly agree with the question and this constitutes $70 \%$ of the whole respondents, 31 respondents agree with the question and this gives $20.67 \%$ of the total respondents while 10 respondents disagree with the question and this represent $6.67 \%$ of the total respondents. Therefore, we can then conclude that fraud can liquidate a bank if is not properly managed with good monitoring information.

Q8: The lacks of current automates system has a significant effect on internet banking services.

147 respondents strongly agree with the question and gives 985 of the total respondents while 3 respondents agree with the question and this represent $2 \%$ of the total respondents, Therefore we can then conclude that the lacks of current automates system has a significant effect on internet banking services.

Q9: The cost of design and implementation of computerized banking monitoring information has a significant effect on Zenith bank Performance in Nigeria.

147 respondents strongly agree with the question and gives 985 of the total respondents while 3 respondents agreed with the question and this represent $2 \%$ of the total respondents, Therefore we can then conclude that the cost of design and implementation of computerized banking monitoring information has a significant effect on Zenith bank Performance in Nigeria.

Q10: Feasibility in installing computerized monitoring system has a significant effect on banking activities in Zenith bank.

The result shows that 147 respondents strongly agree with the question and gives 985 of the total respondents while 3 respondents agree with the question and this represent $2 \%$ of the total respondents, Therefore we can then conclude that feasibility in installing computerized monitoring system has a significant effect on banking activities in Zenith bank.

\section{Result Of The Spearman's Rank Correlation CoefficientHypothesis One}

Null Hypothesis (Ho): The lacks of security on the current automates system has no significant effect on internet banking services.

Alternative Hypothesis (H1): The lacks of security on the current automates system has a significant effect on internet banking services. 
Impact Of Computerized Banking Monitoring Information System On The Performance Of ....

Spearman's Rank Correlations Coefficient Result for Research Hypothesis 1

\begin{tabular}{|c|c|c|c|}
\hline 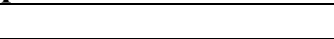 & & Q1 & Q9 \\
\hline $\begin{array}{ll}\text { Spearman's rho } & \text { Q1 } \\
& \text { Q9 }\end{array}$ & $\begin{array}{l}\text { Correlation Coefficient } \\
\text { Sig. (2-tailed) } \\
\text { N } \\
\text { Correlation Coefficient }\end{array}$ & $\begin{array}{c}1.000 \\
\\
50 \\
.883 * *\end{array}$ & $\begin{array}{c}.883 * * \\
.000 \\
150 \\
1.000 \\
\end{array}$ \\
\hline & $\begin{array}{l}\text { Sig. }(2 \text { tailed }) \\
\mathrm{N}\end{array}$ & $\begin{array}{r}.000 \\
150\end{array}$ & 150 \\
\hline
\end{tabular}

\section{Source: Spss Package}

Spearman's correlation co-efficient $\mathrm{r}=.883^{* *}$. Here we have a strong but positively significant relationship is established as reflected in the Spearman's correlation co-efficient $r=0.883$, therefore since H calculated is greater than $\mathrm{H}$ tabulated, using 5\% $=0.05$ level of significance, we then accept alternative hypothesis and reject null hypothesis, then conclude that the lacks of security in the current automates system has a significant effect on internet banking services.

\section{Hypothesis Two}

Null Hypothesis (Ho): The cost of design and implementation of computerized banking monitoring information has no significant effect on Zenith bank Performance in Nigeria.

Alternative Hypothesis (H1): The cost of design and implementation of computerized banking monitoring information has no significant effect on Zenith bank Performance in Nigeria.

\section{Spearman's Rank Correlations Coefficient Result for Research Hypothesis 2}

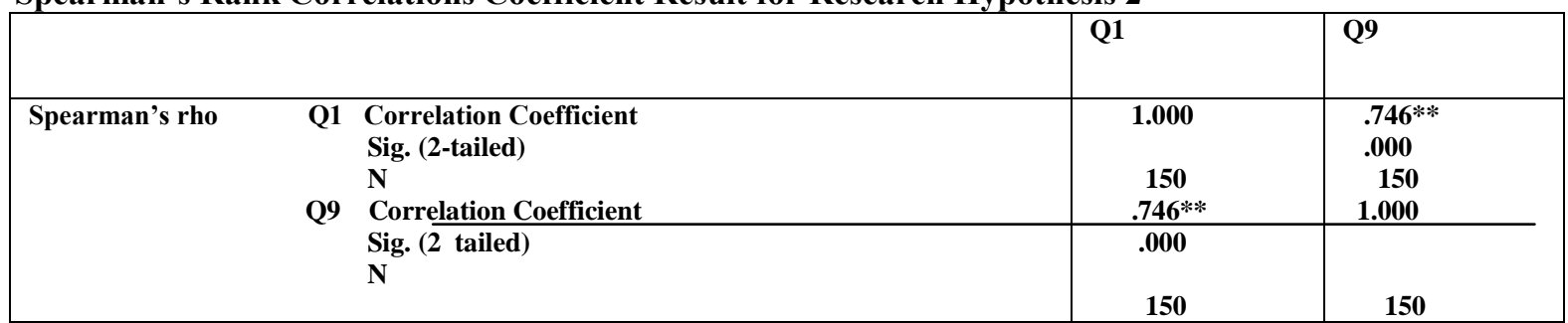

\section{Source: SPSS PACKAGE}

Spearman's correlation coefficient $r=.746^{* *}$.

Here we have a strong and positively significant relationship is established as reflected in the spearman's correlation coefficient $\mathrm{r}=0.746^{* *}$. Here we have a strong but positive significant relationship, however, Since $\mathrm{H}$ calculated (0.746) is greater than $\mathrm{H}$ tabulated using $5 \%$ level of significance $(0.05)$, we then accept the alternative hypothesis and reject the null hypothesis. We can then conclude that the cost of design and implementation of computerized banking monitoring information has no significant effect on Zenith bank Performance in Nigeria.

\section{Hypothesis Three}

Null Hypothesis (Ho): Feasibility in installing computerized monitoring system has no significant effect on banking activities in Zenith bank.

Alternative Hypothesis (H1): Feasibility in installing computerized monitoring system has a significant effect on banking activities in Zenith bank.

Spearman's Rank Correlations Coefficient Result for Research Hypothesis 3

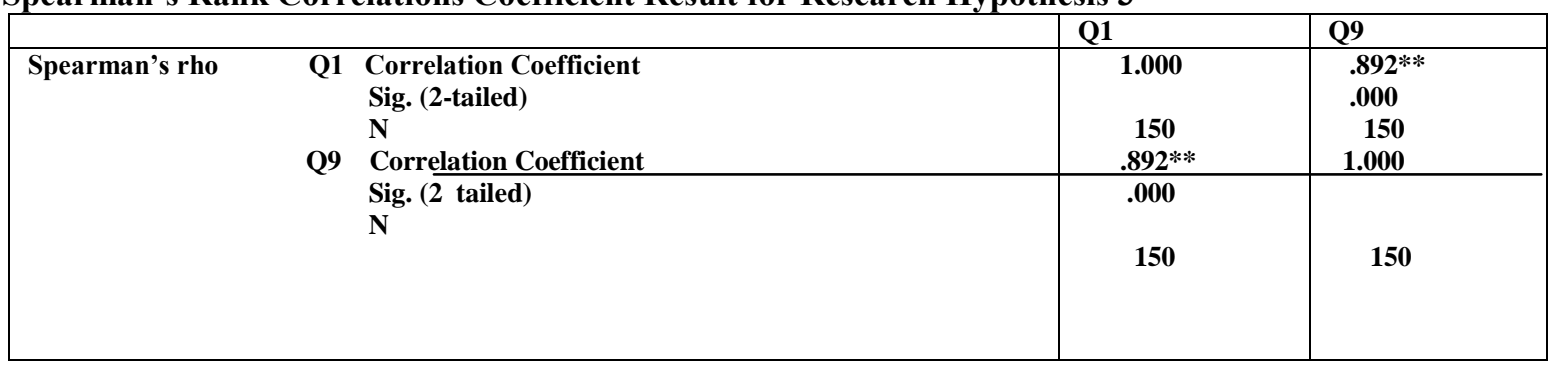

\section{Source: Spss Package}

Spearman's correlation coefficient $r=.892 * *$.

Here we have a strong and positively significant relationship is established as reflected in the spearman's correlation coefficient $r=0.892 * *$. Here we have a strong but positive significant relationship, however, Since $\mathrm{H}$ calculated $(0.9500)$ is greater than $\mathrm{H}$ tabulated using $5 \%$ level of significance $(0.05)$, we then accept the alternative hypothesis and reject the null hypothesis. We can then conclude that feasibility in installing computerized monitoring system has a significant effect on banking activities in Zenith bank. 


\section{The following recommendation given as follows;}

\section{Recommendations}

1. The entire bank should make sure that they acquired and installed computer monitoring technology in the offices and units and branches.

2. Proper check should be done from time to time to make sure there is malfunctioning in the system installed.

3. There should proper maintenance of the system from time to time to avoid damage or loss of information.

4. All the staff of Zenith bank should be dedicated to work and make sure the customer of the bank see value for money.

5. There should be security check from time to time in all the unit, department and branches of the bank.

\section{Conclusion}

When considering using computer monitoring software in the workplace, do extensive research on different products and services. Although some software is costly, it may be worth the investment to protect the integrity of a business. If an organization decides to use this software--inform employees. Allow employees to see the software and its capabilities by demonstrating its features in a group setting. Be open and honest regarding how the software will be used and how it will add security to the business. Talk to employees about their rights regarding computer monitoring. The Nigeria Workforce Commission has policies for workplace computer monitoring and employees should be aware of those policies. Also allow employees to ask questions in a private setting if they wish. Therefore this paper study vividly has done justice to the prevailing topic at hand and my wish is that all stakeholders will make use of the material for further study.

\section{Refrences}

[1]. Awaju, A.F. (2001). Importance of computerize monitoring system in Nigeria, Journal vo 3, pg 44-56, Macmillan Press limited.

[2]. Adams, R.T. (1991). Information Communication Technology and Nigerian Banking Industry, Journal vol 6, pg 18-32, Mill world Press.

[3]. Adelabu, Y.R. (1999). The analysis of Acceptance of Internet banking in Nigeria Banking industry, Macmillan Company limited

[4]. Aganga, F.A. (1991). Movement of Computer System in broader perspective, $2^{\text {nd }}$ edition pg 66-78, MKK Publication limited.

[5]. Brown, S.S. (1991). Computer and its Application, a textbook, $3^{\text {rd }}$ ediion, pg 66-78, Macgrawhill Publication limited.

[6]. Buffalo, A.E. (2012). Security and maintenance of Information system, Journal pg 33-51, MLK Press limited.

[7]. Bill, C.D. (2001). Impact of Computerize Monitoring information System on performance of banking industry, Journal vol 7, pg 66, World press limited.

[8]. Cai, L.I. (2011). Computerise information System and its uses in a formal Organization, Journal vol 6, pg 56, MMK Press limited

[9]. Cai, L.I \&Lipton, H.G. (2012). Information technology in the $21^{\text {st }}$ century, $1^{\text {st }}$ edition, pg 78 MMK PressLimited.

[10]. Dawson, S.A. (2012). Impact of Computerize System of monitoring on bank Performance, Journal vol 19, pg 32-46, Macmillan Publication limited.

[11]. Hamoli,W.T. (2001). Computer and High Speed technology, $2^{\text {nd }}$ edition pg 67-81, DDT Press.Sanya, G.E. (2011). Management of banking software, a Presentation of banking workshop in Nigeria, Nigerian Banker Publication limited.

[12]. Kooker, H.J. (2014). Banking and Fraud Detection, a Contemporary issue, $1^{\text {st }}$ edition, pg 10-34, BBNL Publication limited.

[13]. Williams, M.D. (2001). Impact of Information Technology on Nigerian banking industry, Journal vol 4, pg 76-89, West point Publication limited.

[14]. Young, A.A. (2010). Computer and Fraud in Nigeria Banking industry, $2^{\text {nd }}$ edition, Mac \& Paul Publication Company Limited.

[15]. Zenith bank (1991) The Computer and banking industry, Zenith Publication limited. 